\title{
MAKNA KONTEKSTUAL DALAM CERPEN JEJAK PELANGI DI GUNUNG KENARI KARYA JEFTA H. ATAPENI
}

\author{
Vilentino Daud Atalo ${ }^{1}$ \\ 1701010122 \\ Vilentino2002@gmail.com
}

\begin{abstract}
Karolus B. Jama², Margareta P. E. Djokaho ${ }^{3}$, Karus M. Margareta ${ }^{4}$
Program Studi Pendidikan Bahasa dan Sastra Indonesia, Fakultas Keguruan dan Ilmu Pendidikan, Universitas Nusa Cendana, Jln. Adisucipto Penfui, Kupang 85001, NTT, Telp. (0380) 88639, Fax. 661642

E-mail: fkip-uncyahoo.co.id
\end{abstract}

\begin{abstract}
ABSTRAK
Artikel ini membahas tentang makna kontekstual yang terkandung dalam cerpen Jejak Pelangi di Gunung Kenari Karya Jefta H. Atapeni. Terdapat lima konteks yang dibahas dalam artikel ini, yakni kontkes sosial, konteks politik, konteks situasi, konteks fisik dan konteks budaya. Tujuan penelitian ini adalah mendeskripsikan makna kontekstual yang terkandung dalam cerpen Jejak Pelangi di Gunung Kenari karya Jefta H. Atapeni. Metode yang digunakan dalam penelitian ini adalah deskriptif kualitatif. Teori yang digunakan adalah teori sosiologi karya sastra menurut Wallek dan Warren yang terfokus pada kajian hubungan antara sastra dan masyarakat. Hasil penelitian ini menunjukkan bahwa dari kelima konteks tersebut, yakni konteks sosial, konteks politik, konteks situasi, konteks fisik dan konteks budaya, ditemukan konteks sosial tentang kepedulian sosial antartokoh, konteks politik tentang diskriminasi politik antara penguasa dengan masyarakat kecil; konteks situasi tentang suasana cemas, sunyi, bahagia dan haru; konteks fisik tentang kekerasan fisik yang dilakukan aparat keamanan terhadap Mateu dan konteks budaya tentang perkawinan.
\end{abstract}

Kata kunci: makna, kontekstual, cerpen, sosiologi sastra

\footnotetext{
${ }^{1}$ Penulis

${ }^{2}$ Pembimbing I

${ }^{3}$ Pembimbing II

${ }^{4}$ Penguji
} 


\begin{abstract}
This article discusses the contextual meaning contained in the short story Jejak Pelangi di Gunung Kenari by Jefta H. Atapeni. There are five contexts discussed in this article, namely social context, political context, situational context, physical context and cultural context. The purpose of this study is to describe the contextual meaning contained in the short story Jejak Pelangi di Gunung Kenari by Jefta H. Atapeni. The method used in this research is descriptive qualitative. The theory used is the sociology theory of literary works according to Wallek and Warren which focuses on the study of the relationship between literature and society. The results of this study indicate that from the five contexts, namely social context, political context, situational context, physical context and cultural context, found a social context about social care among figures, political context about political discrimination between rulers and small communities; the context of the situation about the atmosphere of anxiety, silence, happiness and emotion; the physical context of the physical violence perpetrated by the security forces against Mateu and the cultural context of marriage.
\end{abstract}

\title{
Keywords: meaning, contextual, short story, sociology of literature.
}

\section{PENDAHULUAN}

Bahasa merupakan sarana komunikasi yang dimiliki oleh setiap manusia, karena dengan adanya bahasa sebagai alat penyampaian informasi, manusia dapat berkomunikasi. Dalam kehidupan sehari-hari, manusia menerjemahkan bahasa sebagai alat untuk menyalurkan dan mengekspresikan suatu kondisi yang dirasakan. Bahasa akan tersampaikan dengan baik ketika bahasa yang diucapkan memiliki makna. Salah satu makna yang dapat mendukung jalannya interaksi yang baik adalah makna kontekstual. Menurut Chaer (2007:290), makna kontekstual adalah makna sebuah leksem yang berada dalam satu konteks. Makna kontekstual memiliki peran penting dalam suatu karya sastra, karena dengan menggunakan makna kontekstual, pembaca dengan mudah dapat memahami situasi dan tempat terjadinya ujaran, sehingga pembaca dapat menemukan informasi yang tersirat dalam sebuah karya sastra. Semi (1998:8), menerangkan bahwa karya sastra adalah suatu bentuk dan hasil pekerjaan seni kreatif yang objeknya adalah manusia dan kehidupannya menggunakan bahasa sebagai medium. Salah satu wujud karya sastra yang indah ialah cerpen. Cerpen merupakan karya sastra prosa yang lahir dari imajinasi seorang pengarang. Priyatni (2010: 126), cerpen adalah salah satu bentuk karya fiksi.

Cerpen yang diangkat dalam penelitian ini adalah cerpen milik pengarang NTT yang berasal dari Alor. Cerpen "Jejak Pelangi di Gunung Kenari" diambil dari salah satu kumpulan cerpen Jefta H. Atapeni yang berjudul "Percakapan Dengan Laut" cetakan pertama tahun 2016 yang diterbitkan oleh penerbit Framepublishing: Yogyakarta.

Alasan pertama penulis mengambil cerpen Jejak Pelangi di Gunung Kenari sebagai objek penelitian adalah karena cerpen ini menarik untuk dikaji dan menuntut 
peneliti berkontemplasi (merenung) untuk mendapat makna kontekstual yang tersirat di balik cerpen. juga penulis menemukan bahwa kekuatan yang terdapat dalam karya sastra wujud cerpen ini bermuara pada konteks situasi. Karena melalui cerpen ini, pengarang berupaya untuk menggambarkan situasi yang terjadi pada masa pergolakan politik tahun 1965 di Kampung Petleng, agar banyak orang di luar sana pun juga dapat mengetahui peristiwa, keadaan dan kondisi yang terjadi di Kampung Petleng di kala itu. Alasan kedua, cerpen Jejak Pelangi di Gunung Kenari belum dikaji, sehingga peneliti menggunakan pendekatan sosiologi sastra untuk mengupas segala yang tersirat dalam cerpen ini guna menemukan makna kontekstual yang terkandung di dalamnya. Alasan ketiga, karena pengarang berasal dari Nusa Tenggara Timur, dimana peneliti hendak memperkenalkan bahwa potensi sastra khususnya cerpen di NTT masih hidup dan terus berkembang. Dalam pembahasan ini, penulis ingin meneliti tentang makna kontekstual yang berkaitan dengan sastra (cerpen). Adapun beberapa konteks yang akan dibahas dalam penelitian ini, antara lain: (i) konteks sosial, (ii) konteks politik, (iii) konteks situasi, (iv) konteks fisik dan (v) konteks budaya.

\section{METODE PENELITIAN}

Metode yang digunakan dalam penelitian ini ialah deskriptif kualitatif. Moleong (2010: 6), menerangkan bahwa penelitian kualitatif adalah penelitian yang bermaksud untuk memahami fenomena tentang apa yang dialami oleh subjek penelitian secara holistik dan dengan cara deskripsi dalam bentuk kata-kata dan bahasa pada suatu konteks khusus yang alamiah dengan memanfaatkan berbagai metode alamiah. Penelitian ini dilakukan selama enam bulan sejak penulisan proposal sampai pada pelaporan hasil penelitian dalam bentuk skripsi. Data dalam penelitian ini berupa kata-kata dan kalimat makna kontekstual yang terdapat dalam cerpen Jejak Pelangi di Gunung Kenari Karya Jefta H. Atapeni. Adapun sumber data dalam penelitian ini yakni (1) data primer dan (2) data sekunder. Data primer dalam penelitian ini adalah salah satu cerpen yang berjudul Jejak Pelangi di Gunung Kenari. Data sekunder yang dimaksudkan berupa teori-teori yang relevan, penelitian-penelitan terdahulu yang relevan dan jurnal ilmiah.

Pengumpulan data dalam penelitian ini, penulis menggunakan teknik pustaka dan coding card. Tujuan pengkodian ini adalah untuk memberikan ketepatan data pada saat penelitian. Langkah-langkah yang dapat dilakukan adalah sebagai berikut:

1. Membaca sumber data secara cermat;

2. Mengidentifikasi kata-kata yang menggambarkan konteks sosial, konteks politik, konteks situasi, konteks fisik dan konteks budaya;

3. Mengklasifikasikan data berdasarkan makna kontekstual;

4. Memasukkan data ke dalam coding card sesuai dengan konteks sosial, konteks politik, konteks situasi, konteks fisik dan konteks budaya.

Teknik analisis data dalam penelitian ini adalah sebagai berikut:

1. Mengidentifikasi data coding card dengan dengan teks cerpen aslinya;

2. Mengklasifikasi data berdasarkan unit-unit yang dianalisis; 
3. Menganalisis;

4. Mendeskripsikan;

5. Memaparkan hasil penelitian;

6. Menarik simpulan.

\section{HASIL PENELITIAN DAN PEMBAHASAN}

\subsection{Hasil Penelitian}

Data hasil penelitian akan ditampilkan dalam tabel coding card di bawah ini.

\section{TABEL CODING CARD}

No. Unit Analisis

1. Konteks Sosial

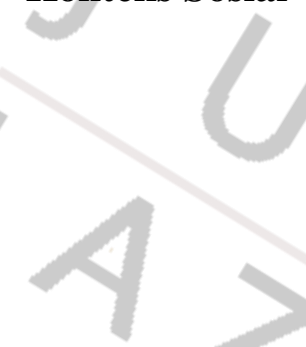

2. Konteks Politik

\section{Konteks Situasi}

\section{Kutipan}

Komandan itu memperhatikan Mateu seolah ia mencari dan menilai sesuatu dalam diri Mateu. Sejenak ia diam memikirkan ucapan Mateu dan muncul belas kasihannya pada Mateu.

Ini cara terakhir saya menolongmu. Cepat turun ke perahu. Mateu segera turun ke perahu lalu komandan melepaskan tali perahu.

Ia diketahui anak seorang petani yang dulu terlibat dalam pemberontakan politik tahun 65 , sehingga ia diperlakukan tidak adil. Namanya diblokir sehingga ia tidak mendapat kesempatan menjadi pegawai negeri sipil.

Ia tak mau pergi karena bukan ia pelaku pembunuhan. Saat itu ia menemukan seorang bapak mati terkapar di kebunnya. Ia hendak menolong, namun beberapa pemuda datang menuduh ia sebagai pelaku pembunuhan. Padahal merekalah yang membunuh karena masalah tanah.

Berulang kali istrinya mendesak supaya Mateu segera pergi menjauh dari Kampung Petleng sebelum para tentara dan polisi datang mencarinya, tapi ia tak mau jauh dari istri dan anak pertamanya yang baru berumur tiga hari.

Mereka punya firasat yang sama, mereka akan dibunuh di kapal dan dibuang ke laut. Suasana hening, kecuali 
bunyi hempasan ombak-ombak kecil di dermaga.

Menjelang magrib itu Kampung Petleng sepi, terlihat seperti kampung mati tak berhantu.

Empat tahun kemudian Joni dan Meri kembali ke Petleng saat ayah Meri meninggal. Semua keluarganya datang melihat Meri dan Joni. Dalam suasana itu, Meri menceritakan seorang bapak di Burain bernama Sem yang mirip Pak Pelang dan Deni.

Ia sangat bahagia mendengar ayahnya SPS masih hidup. Padahal dalam benaknya ia tahu ayahnya telah menjadi bagian dari lautan masa lalu yang tak bisa kembali nyata dalam kehidupannya.

Mendengar cerita Meri, Pak Sem langsung memeluk Meri dan menangis dan katakan ia Mateu, kakak kandung Pelang.

Kehadiran Deni seperti membawa ia total ke bayang-bayang masa lalunya di tanah kelahirannya. Ia tertegun saat Deni menyebut nama dan marganya.

Saat itu Mateu berjanji pada dirinya ia tidak akan kembali ke Alor hingga akhir hayatnya. Air matanya jatuh saat kapal yang ia tumpangi bergerak tinggalkan dermaga dan ia melihat Gunung Kenari di kampungnya.

4. Konteks Fisik

"Kau harus ikut kami ke kantor! Jangan melawan. Ayo jalan!" Perintah komandan itu. Seorang tentara lalu memborgor tangan Mateu dan ia mendorong Mateu keluar dari rumahnya menuju truk.

"Kurang ajar! Kau minta belas kasihan!" Terdengar suara keras seorang prajurut berwajah geram bergerak cepat menuju Mateu dan....Plaaak! Buduuuk! Popor senjatanya mendarat keras di dahi dan dada Mateu. Ia jatuh meringkuk 
menjerit kesakitan.

5. Konteks Budaya

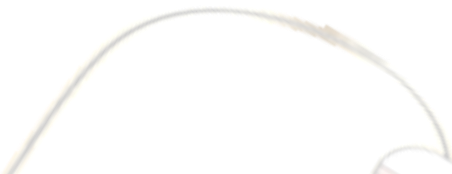

Tiga bulan sebelum Joni kembali ke Burain, ia meminang Meri. Urusan adat dilakukan dan Joni membawa Meri ke Burain.

Sore itu Pak Sem baru pulang mengontrol ternaknya saat Deni dan Joni tiba di rumahnya. "Siapa ini?" tanya Pak Sem pada Joni dengan bahasa Dawan Burain sebelum ia mengulurkan tangannya pada Deni.

Semua keluarganya yakin kalau ia sudah mati sehingga mereka lakukan doa pelepasan Mateu dari Elisabet, lalu Elisabet dikawinkan dengan Pelang, adik kandungnya.
Keterangan:

KS : Konteks Sosial KP : Konteks Politik
KSI : Konteks Situasi KF : Konteks Fisik
KB: Konteks Budaya

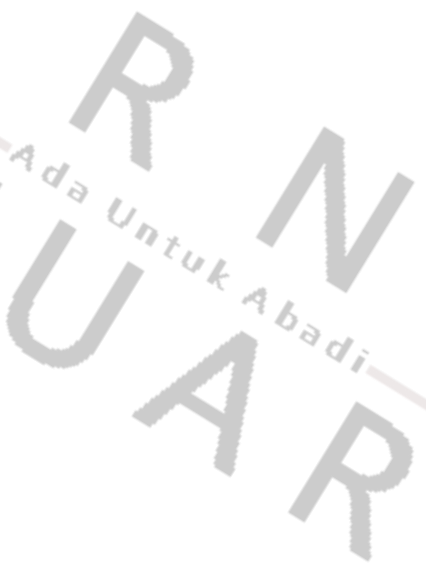




\subsection{Pembahasan}

Hasil penelitian menunjukkan bahwa dalam menganalisis cerpen Jejak Pelangi di Gunung Kenari Karya Jefta H. Atapeni, penulis menemukan konteks sosial tentang kepedulian sosial antartokoh; konteks politik tentang diskriminasi politik antara penguasa dengan masyarakat kecil; konteks situasi tentang suasana cemas, sunyi, bahagia dan haru; konteks fisik tentang kekerasan fisik yang dilakukan aparat keamanan terhadap Mateu dan konteks budaya tentang perkawinan.

konteks tersebut akan ditampilkan di bawah ini.

\section{Konteks Sosial}

"Komandan itu memperhatikan Mateu seolah ia mencari dan menilai sesuatu dalam diri Mateu. Sejenak ia diam memikirkan ucapan Mateu dan muncul belas kasihannya pada Mateu". (hal. 24. paragraf 1.)

Kutipan data 01 di atas merupakan ujaran yang mengandung unsur kepedulian sosial, yakni pada kalimat "muncul belas kasihannya pada Mateu”. Ujaran tersebut mengandung makna tersirat bahwa komandan tentara yang tidak ingin agar Pak Mateu merasakan penderitaan yang sama menimpa dirinya pada waktu ia masih kecil, di mana ayahnya yang dibunuh oleh para tentara Belanda.

Kepedulian sosial pada makna ujaran di atas ialah antara komandan tentara yang merasa iba melihat keadaan Pak Mateu setelah mendengar jawaban Pak Mateu atas pertanyaan yang ia lontarkan terkait dengan perasaan Pak Mateu ketika tahu bahwa mereka akan dibunuh dan dibuang ke laut. Komandan tentara itupun termenung saat mendengar jawaban Pak Mateu yang menceritakan keadaan istri dan anaknya yang baru berumur tiga hari, tentang bagaimana nasib istri dan anaknya itu apabila ia mati. Sekejap, komandan tentara mengingat kejadian masa kecilnya yang hampir sama persis dengan yang sedang diderita oleh Pak Mateu, ketika komandan tentara itu berumur dua bulan, ayahnya dibunuh oleh tentara Belanda. Ia bisa merasakan penderitaan anak Pak Mateu ketika dewasa nanti, namun ia tak mau hal tersebut terjadi pada Pak Mateu, sehingga ia berniat selamatkan Pak Mateu. Pada bagian lain juga akan ditampilkan unsur kepedulian sosial. Seperti pada kutipan data berikut.

Konteks Sosial

"Ini cara terakhir saya menolongmu. Cepat turun ke perahu. Mateu segera turun ke perahu lalu komandan tentara melepaskan tali perahu" (hal 24. paragraf 2.)

Kutipan data di atas merupakan ujaran yang mengandung unsur kepedulian sosial, yakni pada kalimat “Ini cara terakhir saya menolongmu”. Ujaran tersebut mengandung makna tersirat bahwa berbagai cara sudah dilakukan oleh komandan tentara untuk menyelamatkan Pak Mateu dari bahaya yang akan menimpa dirinya. Melepaskan borgol di tangan Pak Mateu pun sudah dilakukan oleh komandan tentara itu ketika komandan tentara menyuruhnya pergi mengambil api di kaki bukit untuk ia membakar rokok, namun Pak Mateu masih tak pahami maksudnya. Cara terakhir pun dilakukan komandan tentara dengan melepaskan borgol di tangan Pak Mateu dan menyuruhnya untuk segera turun ke perahu, lalu komandan tentara melepaskan tali perahu. Pak Mateu terombang-ambing dengan perahu hingga ia lenyap dalam kegelapan. 
Kepedulian sosial pada makna ujaran di atas ialah antara komandan tentara dengan Pak Mateu di mana komandan tentara yang ingin agar Pak Mateu dapat terlepas dari hukuman yang tidak adil itu, sehingga ia dapat kembali hidup bahagia bersama keluarganya yang sedang menunggunya di rumah.

\section{Konteks Politik}

"Setelah Deni tamat SMA, ia bekerja sebagai pegawai honorer di sebuah kantor pemerintah di Kalabahi. Ia diketahui anak seorang petani yang dulu terlibat dalam pemberontakan politik tahun '65, sehingga ia diperlakukan tidak adil. Namanya diblokir, sehingga ia tidak mendapat kesempatan menjadi pegawai negeri sipil" (hal. 20. paragraf 4.)

Kutipan data di atas merupakan ujaran yang mengandung unsur diskriminasi politik, yakni pada kalimat "namanya diblokir, sehingga ia tidak mendapat kesempatan menjadi pegawai negeri sipil”. Ujaran tersebut mengandung makna tersirat bahwa Deni yang tidak tahu menau tentang masalah yang terjadi waktu ia masih bayi, namun mau tidak mau Deni yang dianggap sebagai anak dari pemberontak partai politik terlarang musuh besar negara itu harus menerima kenyataan pahit yang menimpa dirinya. Di mana setelah Deni tamat SMA, ia bekerja sebagai pegawai honorer di sebuah kantor pemerintah di Kalabahi, ia selalu mengikuti seleksi pengangkatan menjadi Pegawai Negeri Sipil, namun ia selalu gagal karena namanya tak pernah diterima oleh pihak pemerintahan. Ia tabah dan setia bekerja sebagai pegawai honorer selama belasan tahun. Ia tidak patah semangat dan menyerah jalani pekerjaan itu. Pulang dari kantor ia bekerja di tanah garapannya, menanam sayur dan buah untuk dijual istrinya

Diskriminasi politik pada makna ujaran di atas ialah antara lembaga pemerintahan dan Deni, anak Mateu yang dulunya dituduh membunuh seorang bapak di kebunnya, padahal ia sendiri pun tak tahu siapa pelaku pembunuhan. Dari sini dapat dilihat bahwa munculnya ketidakadilan; yang menggambarkan bahwa bengisnya pergolakan politik zaman itu bisa dianggap tak ada lagi nurani dalam diri orang-orang yang selalu menggunakan kekuasaan mereka untuk menindas rakyat kecil. Pada bagian lain juga akan ditampilkan unsur politik. Seperti pada kutipan data berikut.

\section{Konteks politik}

"Ia tak mau pergi karena bukan ia pelaku pembunuhan. Saat itu ia menemukan seorang bapak mati terkapar di kebunnya. Ia hendak menolong, namun beberapa pemuda datang menuduh ia sebagai pelaku pembunuhan. Padahal merekalah yang membunuh karena masalah tanah" (hal. 19. paragraf 1)

Kutipan data di atas merupakan ujaran yang mengandung unsur politik, yakni pada kalimat "Ia hendak menolong, namun beberapa pemuda datang menuduh ia sebagai pelaku pembunuhan". Ujaran tersebut mengandung makna tersirat bahwa pada saat Pak Mateu sedang berada untuk bekerja di kebunnya seperti biasa, tanpa sengaja ia melihat ada sosok jasad seorang bapak yang terkapar di situ. Pak Mateu yang merasa kaget saat melihat kejadian itu, kemudian ia bergegas untuk membawa pergi jasad bapak itu ke tempat yang layak, namun pada saat ia hendak membawa jasad bapak itu, tiba-tiba sekelompok pemuda menyergap Pak Mateu dan langsung menuduh Pak Mateu bahwa dia lah yang yang membunuh bapak itu. Padahal kenyataannya, para sekelompok pemuda itulah yang membunuh dan membuang jasad bapak itu ke kebunnya Pak Mateu karena masalah tanah.

Konteks politik pada makna ujaran di atas menggambarkan bahwa betapa ironisnya permainan politik di kala itu, sehingga orang yang tak bersalah pun rela dikhianati demi kesenangan sejumlah orang. Keserakahan beberapa warga di Kapung Petleng itu terlihat jelas pada perilaku mereka yang mau menopoli tanah milik orang lain, sehingga cara najis sekalipun mereka lakukan demi mendapatkan apa yang mereka mau atau apa yang menjadi 
tujuan mereka, dan yang lebih tak bermoral ialah perbuatan najis tersebut mereka tuduhkan kepada rakyat lain yang tidak bersalah.

Konteks Situasi

"Berulang kali istrinya mendesak supaya Mateu segera pergi menjauh dari Kampung Petleng sebelum para tentara dan polisi datang mencarinya, tapi ia tak mau jauh dari istri dan anak pertamanya yang baru berumur tiga hari" (hal. 19. paragraf 1)

Kutipan data di atas merupakan ujaran yang mengandung unsur kecemasan, yakni pada kalimat “Istrinya mendesak supaya Mateu segera pergi menjauh dari kampung Petleng”. Ujaran tersebut mengandung makna tersirat bahwa Elisabet yang sangat mencintai suaminya itu tidak mau suaminya, Mateu ditangkap dan dibawa pergi oleh aparat keamanan yang datang di rumahnya.

Konteks situasi pada makna ujaran di atas menggambarkan tentang kecemasan Elisabet ketika ia mengetahui bahwa sejumlah tentara dan polisi akan datang menangkap suaminya, Pak Mateu di rumah. Ia tak mau suami yang dicintainya itu dibawa pergi oleh aparat keamanan pemerintah, sehingga ia terus mendesak agar pak Mateu segera pergi menjauh dari Kampung Petleng. Pada bagian lain juga akan ditampilkan unsur kecemasan. Seperti pada kutipan data berikut.

Konteks Situasi

"Mereka punya firasat yang sama, mereka akan dibunuh di kapal dan dibuang ke laut. Suasana hening, kecuali bunyi hempasan ombak-ombak kecil di dermaga” (hal. 23. paragraf 2)

Kutipan data di atas, merupakan ujaran yang mengandung unsur kecemasan, yakni pada kalimat “Mereka punya firasat yang sama, mereka akan dibunuh dan dibuang ke laut”. Ujaran tersebut mengandung makna tersirat bahwa setelah dituduh melakukan masalah pembunuhan dan sejumlah masalah lainnya, Mateu dan beberapa tahanan lainnya kemudian ditangkap dan mereka semua dibawa ke atas kapal dan akan dieksekusi mati oleh para tentara. Meskipun mereka tidak mengetahui pasti, apakah mereka akan dibawa ke suatu tempat untuk direhabilitasi atau dipenjara, namun yang mereka semua pikirkan hanyalah kematian yakni akan ditembak mati dan dibuang ke dalam laut.

Konteks situasi pada makna ujaran di atas menggambarkan tentang ketakutan, kekhawatiran dan kepasrahan yang tinggal dalam diri tiap para tahanan. Karena mereka tahu bahwa sebentar lagi mereka akan dibunuh di kapal dan dibuang ke laut.

Selain situasi cemas, adapun situasi sunyi yang tersirat dalam isi cerpen. Kesunyian merupakan sebuah kondisi di mana tidak adanya aktifitas yang menghasilkan keramaian.

Konteks Situasi

“Menjelang magrib itu Kampung Petleng sepi, terlihat seperti kampung mati tak berhantu” (hal. 19. paragraf 1)

Kutipan data di atas merupakan ujaran yang mengandung unsur kesunyian, yakni pada kalimat “Kampung Petleng sepi, seperti kampung mati tak berhantu”. Ujaran tersebut mengandung makna tersirat bahwa setelah penangkapan pak Mateu dan sejumlah warga di Kampung Petleng, warga lainnya di kampung itu hanya berdiam diri di dalam rumah mereka masing-masing. Mereka takut dengan peristiwa yang telah menimpa Pak Mateu dan sejumlah warga lainnya itu juga akan menimpa mereka, sehingga segala aktifitas para warga yang dilakukan di kampung itu tak terlihat seperti biasanya. 
Konteks situasi pada makna ujaran di atas menggambarkan tentang kesunyian yang terjadi di Kampung Petleng usai peristiwa penangkapan Pak Mateu dan sejumlah orang. Selain situasi cemas dan sunyi, adapun situasi sedih yang tersirat dalam isi cerpen. Kesedihan merupakan emosi yang dipicu oleh suatu peristiwa, pengalaman, hingga situasi yang menyakitkan dan mengecewakan. Seperti pada kutipan data berikut.

Konteks Situasi

"Empat tahun kemudian Joni dan Meri kembali ke Petleng saat ayah Meri meninggal. Semua keluarganya datang melihat Meri dan Joni. Dalam suasana itu, Meri menceritakan seorang bapak di Burain bernama Sem yang mirip Pak Pelang dan Deni" (hal. 21. paragraf 1)

Kutipan data di atas merupakan ujaran yang mengandung unsur kesedihan, yakni pada kalimat "Dalam suasana itu, Meri menceritakan seorang bapak di Burain bernama Sem yang mirip Pak Pelang dan Deni. Ujaran tersebut mengandung makna tersirat bahwa adanya rasa kekaguman bercampur haru yang timbul dalam diri Meri pada waktu ia berada di Burain dan melihat Pak Sem yang mirip dengan Pak Pelang dan Deni. Tak hanya itu, dalam lubuk hati yang paling dalam, Meri tahu bahwa ada sesuatu di antara saudara tirinya itu dengan Pak Sem. Sesuatu yang tidak biasa, sesuatu yang ingin sekali berjumpa setelah sekian lama berpisah.

Konteks situasi pada makna ujaran di atas menggambarkan bahwa meskipun keadaan sedang dalam nuansa berduka, Meri datang membawa kabar gembira khususnya untuk Ibu Elisabet dan Deni perihal suami Ibu Elisabet yang dulu katanya telah dibunuh dan dibuang ke laut itu masih hidup dan kini menetap di Burain dan samarkan dirinya menjadi Pak Sem.

Selain situasi cemas, sunyi, dan sedih adapun situasi bahagia yang tersirat dalam isi cerpen. Kebahagiaan merupakan suatu keadaan pikiran atau perasaan yang ditandai dengan kecukupan hingga kegembiraan yang intens. Seperti pada kutipan data berikut.

\section{Konteks Situasi}

"Ia sangat bahagia mendengar ayahnya masih hidup. Padahal dalam benaknya ia tahu ayahnya telah menjadi bagian dari lautan masa lalu yang tak bisa kembali nyata dalam kehidupannya” (hal. 22. paragraf 2)

Kutipan data di atas merupakan ujaran yang mengandung unsur kebahagiaan, yakni pada kalimat "Ia sangat bahagia mendengar ayahnya masih hidup”. ujaran tersebut mengandung makna tersirat bahwa setelah kembalinya Meri dari Burain ke Petleng pada saat ayah Meri meninggal, Meri menceritakan kepada Ibu Elisabet dan beberapa warga yang ikut duduk bersama dengan mereka pada saat itu, Meri bercerita bahwa ia telah bertemu dengan dengan Pak Mateu yang saat ini samarkan dirinya menjadi Pak Sem.

Konteks situasi pada makna ujaran di atas menggambarkan bahwa betapa bahagianya Deni setelah mendengar ucapan Ibunya, Elisabet tentang ayahnya, Pak Mateu yang masih hidup dan kini sedang berada di Burain, samarkan dirinya menjadi Pak Sem. Padahal dalam benak Deni, ia takkan lagi bertemu dengan ayahnya yang telah menjadi bagian dari cerita masa lalu yang tidak bisa kembali bersama. Selain situasi cemas, sunyi, sedih dan bahagia, adapun situasi haru yang tersirat dalam isi cerpen. Haru merupakan rekasi iba yang timbul dari dalam diri seseorang akibat mendengar atau melihat sesuatu. Seperti pada kutipan data berikut. 
"Mendengar cerita Meri, Pak Sem langsung memeluk Meri dan menangis dan katakan ia Mateu, kakak kandung Pelang" (hal. 21. paragraf 1)

Kutipan data di atas merupakan ujaran yang mengandung unsur haru, yakni pada kalimat “Pak Sem langsung memeluk Meri dan menangis". Ujaran tersebut mengandung makna tersirat bahwa pada saat Meri dibawa oleh Joni ke Burain, Meri melihat seorang bapak di sana yang rupanya mirip dengan ayahnya dan saudara tirinya. Meri menyapa Pak Sem dan mereka bercerita, lalu Meri menceritakan asal-usul Meri kepada Pak Sem bahwasannya Meri adalah anak dari Pak Pelang, adik kandung Pak Sem.

Konteks situasi pada makna ujaran di atas menggambarkan bahwa suasana haru sudah tak terbendung lagi ketika Meri bercerita bahwa kakak Pak Pelang, yakni Pak Mateu telah dibunuh dan dibuang ke laut dan istrinya dikawinkan dengan adik kandungnya Pak Pelang dan Meri salah satu keturunannya. Saat itu juga, Pak Sem mengatakan pada Meri kalau dirinya adalah Mateu yang adalah kakak kandung ayah Meri, Pak Pelang yang kini samarkan dirinya menjadi Pak Sem. Pada bagian lain juga akan ditampilkan unsur haru. Seperti pada kutipan data berikut.

\section{Konteks Situasi}

"Kehadiran Deni seperti membawa ia total ke bayang-bayang masa lalunya di tanah kelahirannya. Ia tertegun saat Deni menyebut nama dan marganya" (hal 22. Paragraf 4)

Kutipan data di atas merupakan ujaran yang mengandung unsur haru, yakni pada kalimat “Ia tertegun saat Deni menyebut nama dan marganya". Ujaran tersebut mengandung makna tersirat bahwa pada saat Pak Mateu baru saja pulang mengontrol ternaknya di kebun, ia melihat Joni sedang duduk dengan seorang lelaki di rumahnya. Pak Mateu bertanya pada Joni tentang siapa laki-laki yang duduk dengan Joni dalam bahasa Dawan Burain, sebelum ia mengulurkan tangannya pada Deni. Mereka pun duduk bercerita dan Joni mengakatan bahwa Deni adalah saudara tirinya. Pak Mateu diam sejenak saat Deni mengatakn bahwa dia adalah anak Pak Pelang, kakak kandung Pak Mateu.

Konteks situasi pada makna ujaran di atas menggambarkan bahwa di saat pertemuan Deni dan ayahnya, Pak Mateu, suasana haru sudah tak terbendung lagi di antara mereka berdua setelah 34 tahun lamanya mereka berpisah dan akhirnya dapat bertemu kembali dan berpelukan dalam kebahagiaan. Pada bagian lain juga akan ditampilkan unsur haru. Seperti pada kutipan data berikut.

\section{Konteks Situasi}

"Saat itu Mateu berjanji pada dirinya ia tidak akan kembali ke Alor hingga akhir hayatnya. Air matanya jatuh saat kapal yang ia tumpangi bergerak tinggalkan dermaga dan ia melihat Gunung Kenari di kampungnya”. (hal. 24. paragraf 2)

Kutipan data di atas merupakan ujaran yang mengandung unsur haru, yakni pada kalimat “Air matanya jatuh saat kapal yang ia tumpangi bergerak tinggalkan dermaga”. Ujaran tersebut mengandung makna tersirat bahwa lima tahun kemudian setelah peristiwa penangkapan itu, Pak Mateu samarkan dirinya dan kembali ke Kalabahi untuk bertemu dengan istri dan anaknya, namun saat Mateu kembali ke Kampung halamannya, ia mendapati kalau istrinya, Elisabet telah dikawinkan dengan pelang. Mateu berjanji pada dirinya sendiri bahwa ia takkan lagi kembali ke Alor untuk menemui, Elisabet. 
Konteks situasi pada makna ujaran di atas menggambarkan bahwa Pak Mateu yang tengah bersedih dan sudah tak punyai harapan untuk kembali hidup bersama-sama dengan Elisabet, karena keluarganya telah lakukan ritual adat dan doa pelepasan Mateu dan Elisabet, sehingga Mateu sudah tak punyai harapan untuk bisa hidup kembali bersama-sama dengan Elisabet.

\section{Konteks Fisik}

"Kau harus ikut kami ke kantor! Jangan melawan. Ayo jalan!" Perintah komandan itu. Seorang tentara lalu memborgol tangan Mateu dan ia mendorong Mateu keluar dari rumahnya menuju truk". (hal. 20. paragraf 3)

Kutipan data di atas merupakan ujaran yang mengandung unsur kekerasan fisik, yakni pada kalimat “Kau harus ikut kami ke kantor! Jangan melawan. Ayo jalan”. Ujaran tersebut mengandung makna tersirat bahwa Mateu membela dirinya dan melawan ketika para tentara dan polisi datang menangkap ia di rumahnya. Ia bersih keras kalau bukan ia pelaku pembunuhan seorang bapak di kebunnya. Pak Mateu sempat melawan, namun apalah daya Pak Mateu yang hanya masyarakat biasa dan tak memiliki kekuatan fisik untuk melawan para aparat keamanan pemerintah itu, akhirnya Pak Mateu pun pasrah dibawa pergi oleh mereka.

Konteks kekerasan fisik pada makna ujaran di atas menggambarkan bahwa aparat keamanan pemerintah datang ke rumah Pak Mateu, memborgol tangannya lalu membawa Pak Mateu ke kantor dengan cara paksa.

\section{Konteks Fisik}

"Kurang ajar! Kau minta belas kasihan!" Terdengar suara keras seorang prajurut berwajah geram bergerak cepat menuju Mateu dan....Plaaak! Buduuuk! Popor senjatanya mendarat keras di dahi dan dada Mateu. Ia jatuh meringkuk menjerit kesakitan". (hal. 23. paragraf 4)

Kutipan data di atas merupakan ujaran yang mengandung unsur kekerasan fisik, yakni pada kalimat "Popor senjatanya mendarat keras di dahi dan dada Mateu dan ia jatuh meringkuk kesakitan". Ujaran tersebut mengandung makna tersirat bahwa pada saat penangkapan Pak Mateu, dirinya masih melawan sehingga anggota tentara langsung menghantam dada dan dahi Mateu dengan popor senjata.

Konteks fisik pada makna ujaran di atas menggambarkan bahwa kekerasan yang menjadi tujuan utama dari para anggota tentara itu. Tak hanya itu, itikad baik dalam diri para tiap anggota tentara di zaman itu sudah tak ada. Sepatah ucapan yang muncul dari bibir para tahanan akan dianggap sebagai kesalahan dan akan langsung dihajar dengan tangan kosong maupun popor senjata yang mereka pegang.

\section{Konteks Budaya}

"Tiga bulan sebelum Joni kembali ke Burain, ia meminang Meri. Urusan adat dilakukan dan Joni membawa Meri ke Burain” (hal 20. paragraf 5)

Kutipan data di atas merupakan ujaran yang mengandung unsur kebudayaan, yakni pada kalimat "Urusan adat dilakukan dan ia membawa Meri ke Burain". Ujaran tersebut mengandung makna tersirat bahwa setelah Joni dan Meri direstui oleh keluarga mereka untuk dikawinkan, maka upacara adat pun dilakukan agar Meri bisa dibawa pergi ke daerah asal Joni, yakni Burain.

Konteks budaya pada makna ujaran di atas menggambarkan tentang keseriusan Joni dalam hubungan percintaan dengan anak Pak Pelang, Meri, sehingga dilakukannya urusan adat agar Meri seutuhnya menjadi istri Joni. Pada bagian lain juga akan ditampilkan unsur kebudayaan. Seperti pada kutipan data berikut. 
"Sore itu Pak Sem baru pulang mengontrol ternaknya saat Deni dan Joni tiba di rumahnya. "Siapa ini?" tanya Pak Sem pada Joni dengan bahasa Dawan Burain sebelum ia mengulurkan tangannya pada Deni”. (hal. 22. paragraf 3)

Kutipan data di atas merupakan ujaran yang mengandung unsur kebudayaan, yakni pada kalimat "Siapa ini?, tanya Pak Sem pada Joni dengan bahasa Dawan Burain". Ujaran tersebut mengandung makna tersirat bahwa ketika peristiwa penangkapan Pak Mateu di Kampung Petleng yang kemudian ia dibawa pergi oleh aparat keamanan untuk dieksekusi mati, namun nyawanya masih dapat tertolong oleh komandan tentara yang merasa kasihan melihat keadaan Pak Mateu. Setelah peristiwa itu, kemudian Pak Mateu samarkan dirinya menjadi Pak Sem dan ia menetap di Burain.

Konteks budaya pada makna ujaran di atas menggambarkan bahwa setelah Pak Mateu bertolak ke Burain dan menetap di sana, ia kemudian menikah dengan seorang perempuan Burain dan mereka dikarunia lima orang anak. Pak Mateu yang telah menjadi warga Burain tentunya terikat dengan keseharian budaya berbahasa di sana yang menggunakan bahasa daerah sebagai bahasa utama dalam berkomunikasi, dan seiring berjalannya waktu, pak mateu pun menjadi fasih berbahasa daerah Dawan Burain.

\section{Konteks Budaya}

"Semua keluarganya yakin kalau ia sudah mati sehingga mereka lakukan ritual adat dan doa pelepasan Mateu dari Elisabet, lalu Elisabet dikawinkan dengan Pelang, adik kandungnya". (hal. 24. paragraf 2)

Kutipan data di atas merupakan ujaran yang mengandung unsur kebudayaan, yakni pada kalimat "Elisabet dikawinkan lagi dengan Pelang, adik kandungnya". Ujaran tersebut mengandung makna tersirat bahwa ketika sudah tak ada lagi kabar tentang Pak Mateu selama kurang lebih lima tahun sejak penangkapannya, dan demi merawat ia dan anaknya, maka Elisabet dikawinkan lagi dengan Pelang, adik kandung Pak Mateu.

Konteks budaya pada makna ujaran di atas menggambarkan bahwa setelah semua keluarga mengetahui bahwa Pak Mateu telah meninggal, maka mereka sepakat untuk mengawinkan Ibu Elisabet dengan adik kandung dari Pak Mateu, yakni Pak Pelang. Karena Pak Pelang adalah adik kandung dari Pak Mateu, maka perkawinan ia dan Ibu Elisabet itu dilakukan tanpa lagi harus membayar belis (mahar), karena Pak Pelang memakai belis dari sang kakak, dan sebelum masuk ke acara prosesi pernikahan, mereka terlebih dahulu lakukan ritual adat dan doa pelepasan arwah Pak Mateu dengan cara ketua adat mendoakan jasad Pak Mateu kepada leluhur semesta alam agar rohnya tenang bersama dengan para leluhur. Barulah prosesi pernikahan Pak Mateu dan Ibu Elisabet dilakukan. Upacara adat dan doa pelepasan serta perkawinan tersebut merupakan sesuatu yang sah dan sakral.

\section{PENUTUP}

\subsection{Simpulan}

Berdasarkan hasil penelitian dalam cerpen Jejak Pelangi di Gunung Kenari karya Jefta H. Atapeni yang telah disajikan dalam BAB IV, maka peneliti menemukan konteks sosial tentang kepedulian sosoal antartokoh; konteks politik tentang diskriminasi politik antara penguasa dengan masyarakat kecil; konteks situasi tentang suasana cemas, sunyi, bahagia dan haru; konteks fisik tentang kekerasan fisik yang dilakukan aparat keamanan terhadap Mateu dan konteks budaya tentang perkawinan. 
Berdasarkan simpulan hasil analisis, kelima konteks dalam teks cerpen Jejak Pelangi di Gunung Kenari karya Jefta H. Atapeni, yakni konteks sosial, konteks politik, konteks situasi, konteks fisik dan konteks budaya di atas, maka penulis menemukan bahwa kekuatan yang terdapat dalam karya sastra wujud cerpen ini bermuara pada konteks situasi. Karena melalui cerpen ini, pengarang berupaya untuk menggambarkan situasi yang terjadi pada masa pergolakan politik tahun 1965 di Kampung Petleng, sehingga banyak orang di luar sana pun juga dapat mengetahui peristiwa, keadaan dan kondisi yang terjadi di Kampung Petleng di kala itu.

\subsection{Saran}

Peneliti berikut harus giat dalam menggali informasi dan banyak sumber mengenai makna kontekstual, baik itu dalam cerpen, novel dan karya tulis lainnya, sehingga dapat mencapai tujuan yang maksimal. Juga peneliti menyarankan kepada masyarakat umum sebagai pembaca agar jangan bosan dalam hal membaca, khususnya tentang makna kontekstual dalam cerpen, sehingga dapat meningkatkan pengetahuan tentang bagaimana menganaisis cerpen dengan menggunakan pendekatan sosiologi sastra.

\section{DAFTAR PUSTAKA}

Akhadiah, A. \& Ridwan. 2002. Pembinaan Kemampuan Menulis Bahasa. Jakarta: Erlangga.

Asriati, A. D. 2018. Analisis Makna Kontekstual Pada Iklan Niaga Di Harian Waspada Medan. Skripsi. Sumatera Utara: Universitas Muhamadiyah.

Badudu, J.S. 1975. Pelik-Pelik Bahasa Indonesia. Bandung: TB Bandung.

Baryadi, I. P. 2015. Teori-teori Linguistik Pascastruktural Memasuki Abad ke-21. Yogyakarta: PT. Kanisius.

Chaer, A. 1994. Linguistik Umum. Jakarta: Rineka Cipta.

2007. Linguistik Umum cetakan ketiga. Jakarta: Rineka Cipta.

Damono, D. S. 1984. Sosiologi Sastra sebuah Pengantar Ringkas. Jakarta: Pusat Pembinaan dan Pengembangan Bahasa Departemen Pendidikan dan Kebudayaan.

Edi S. D. 2007. Pengantar Metode Penelitian Linguistik Struktural. Surakarta: Universitas Sebelas Maret Press.

Heryanto, A. 1985. Pengantar Sosiologi Sastra. Yogyakarta: Medpress.

Http://ibezcom.blogspot.com/2013/12/pengertian-cerpen.html.

Kosasih, dkk. 2004. Bahasa dan Sastra Indonesia. Jakarta: Erlangga.

Kridalaksana, H. 2011. Kamus Linguistik. Jakarta: Gramedia Pustaka.

Malo, Y. 2016. Makna Kontekstual Lokalitas Sumba Dalam Antologi Puisi Gemersik Ilalang Padang Sabana Karya Agust Dapa Loka. Skripsi. Kupang: Universitas Nusa Cendana.

Mardiana, A. N. D. 2020. Analisis Makna Kontekstual Bahasa Dalam Iklan Cat Tembok Di Televisi. Tuah Talino Tahun XIV - Vol.14. No. 2 Edisi 4 Desember 2020. Balai Bahasa Kalimantan Barat, 185-194.

Mashun. 2012. Metode Penelitian Bahasa Tahapan Strategi. (Metode dan Tekniknya). Jakarta: Rajawali Pers.

Moelong, L. J. 2010. Metodologi Penelitian Kualitatif. Bandung: Remaja Rosdakarya.

Mulyana, D. 2008. Ilmu Komunikasi: Suatu Pengantar. Bandung: remaja Rosakarya.

Nadar, F. X. 2009. Pragmatik dan Penelitian Pragmatik. Yogyakarta: Graha Ilmu.

Nofitasari, Y. 2015. Analisis Makna Kontekstual Gurindam ABAD 21: Berkelana di Padang Fana Karya Eko Maulana Ali. Artikel E-Journal. Tanjung Pinang: Universitas Maritim Raja Ali Haji. 
Palimbong, R. D. 2015. Makna Kontekstual Dalam Novel Diary Pramugari Karya Agung Webe. JURNAL KIP - Vol. IV. No. 2, Juli 2015 - Oktober 2015, 915-926.

Pateda, M. 2010. Semantik Leksikal. Jakarta: Rineka Cipta.

Priyatni, E. T. 2010. Membaca Sastra Dengan Ancaman Literasi Kritis. Jakarta: Bumi Aksara.

Rahardi, K. 2005. Pragmatik: Kesatuan Imperatif Bahasa Indonesia. Jakarta: Erlangga.

Semi, A. 1998. Anatomi Sastra. Padang: Angkasa Raya.

Soekanto, S. 1990. Sosiologi Suatu Pengantar. Jakarta: Raja Grafindo Persada.

Sudaryat, Y. 2009. Makna Dalam Wacana. (Prinsip-prinsip Semantik dan Pragmatik). Bandung: Yrama Widya.

Sumarlam. 2006. Analisis Wacana Tekstual dan Kontekstual. Surakarta: UNS Press.

Tarigan, H.G. 1984. Prinsip-Prinsip Dasar Sastra. Bandung: Angkasa.

Teeuw. 2003. Sastra dan Ilmu Sastra. Jakarta: Dunia Pustaka Jaya.

Ullman, S. 2007. Pengantar Semantik. Yogyakarta: Pustaka Belajar.

Wellek, R. dan Warren, A. 1990. Teori Kesusastraan (Diterjemahkan Oleh Melani Budianta), Jakarta: Pustaka Jaya. 